\title{
A REVIEW OF THE EFFECT OF BASALT FIBRE LENGTHS AND PROPORTIONS ON THE MECHANICAL PROPERTIES OF CONCRETE
}

\author{
Sami Elshafie ${ }^{1}$, Gareth Whittleston ${ }^{2}$ \\ ${ }^{I}$ Ph.D Civil Engineering Student, The University of Bolton, Faculty of Advanced Engineering and Sciences, Deane \\ Road, Bolton, UK \\ ${ }^{2}$ Structural Engineering Lecturer, The University of Bolton, Faculty of Advanced Engineering and Sciences, Deane \\ Road, Bolton, UK
}

\begin{abstract}
During the past few decades, the concrete construction field has seen a growing interest in the advantages that fibre reinforcement has to offer. Between the different types of fibres available, basalt fibre is considered a promising new material to use. It has extremely good strength characteristics and thermal resistance, high resistance to an alkaline environment, and is cheap product, making it an excellent material to reinforce concrete. In view of the significance of basalt fibres for concrete, and because different lengths and proportions of basalt fibres have an effect on the mechanical properties of concrete, it is proposed to review the effect of using different basalt fibre lengths and content on the mechanical properties of concrete. The mechanical properties of concrete reviewed are compressive strength, tensile strength, flexural strength, permeability, workability, and unit weight. This paper has for the first time reviewed the current literature related to the effect of using basalt fibres of different proportions on the mechanical properties of concrete, provided future researchers with the information and facts needed to compare their work, and identified the best basalt fibre length and content combination that demonstrates an improvement in the mechanical properties of concrete. From reviewing the literature, it was found that most authors agreed that the mechanical properties of concrete improved significantly when using basalt fibres with a length between $12 \mathrm{~mm}$ and $24 \mathrm{~mm}$, and content between $0.1 \%-0.5 \%$ by total volume. In this context, the length and content of basalt fibres in concrete becomes an important parameter for the mechanical properties of concrete.
\end{abstract}

Keywords: Basalt Fibres, Compressive Strength, Tensile Strength, Flexural Strength, Elastic Modulus, Workability, Permeability, Unit Weight.

\section{INTRODUCTION}

Concrete is known as the construction material most used around the world. It is strong in compression as the aggregates can effectively carry the compression load. However, concrete is weak in tension, as the cement holding the aggregate can crack, causing concrete to break. An effective way to improve the tensile strength of concrete and reduce the number of defects is by adding different fractions of fibres, Youjiang Wang [36]. Fibres can enhance the concrete strength, which enables the construction to withstand external forces. When plain concrete is compressed, it shatters and fails at the first crack. However, fibres are manufactured specially to prevent the effect of shattering forces by tightly holding concrete together, NRMCA [19].

The rapid increase in the use of fibres in concrete is attributed to its positive effect on the mechanical properties of the cementations composites. It is proven that the addition of fibres to concrete has a significant impact on improving the mechanical properties of fresh and hardened concrete, such as compressive strength, tensile strength, flexural strength, and workability.
The use of fibres has undergone major development in the last 30 years, and this composite material has been used successfully in various applications of civil engineering. The current new generation of fibre applications in concrete include Slurry Infiltrated Fibrous Reinforced Concrete (SIFCON), Engineered Cementations Composite (ECC), and Reactive Powder Concrete (RPC), P.K. Mehta [24].

Many types of fibre have been used to reinforce concrete, such as steel, glass, and polyethylene fibre. Of the different fibres available, steel fibres are probably the most investigated and most commonly used. According to S.M Chikhalikar and Tande [29], steel fibres are most commonly used (50\%), followed by polypropylene fibres (20\%) and glass fibres $(5 \%)$, with other types of fibres making up $25 \%$ see (Fig.1). 


\section{Percentages of fibres used in the UK construction industry}

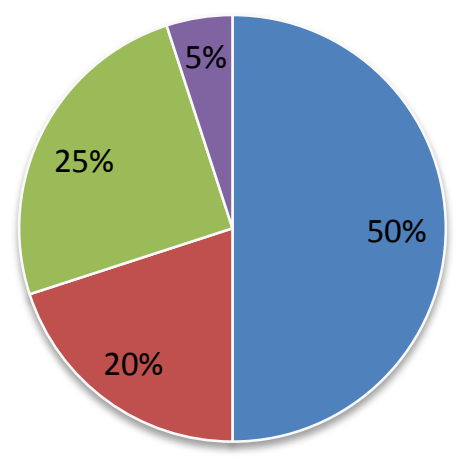

- Steel

- Polyethelyne

- Others

- Glass

Chart. 1: Percentage of fibres used in the UK construction industry

One of the promising new materials used in the construction industry is basalt fibre. It is only in the last few years that extensive research and tests have been conducted on this product, with a view to its application in the building sector. Basalt fibre has a similar chemical composition to glass fibre, but has better strength characteristics and, unlike most glass fibres, is highly resistance to alkaline, acidic and salt attack, making it an excellent product to reinforce concrete. Compared with other types of fibre, its use in the civil engineering market is very low, Richard E.Prince [26].

Basalt is a type of igneous rock formed by the rapid cooling of lava. It is found at a depth of hundreds of kilometres beneath the earth, and it reaches the surface as molten magma. When magma reaches the surface, it cools down and can be mined as a raw material, R. Karthigeyan [27]. Basalt fibre is a material made from extremely fine fibres of basalt, which is composed of several minerals extracted from the basalt volcanic rock. High quality fibres are made from basalt deposits with uniform chemical makeup.

Basalt fibres have excellent characteristics: for instance, they can bond chemically with cement. When water is added to cement, hydration starts, resulting in the production of two main components, which are:

1. CSH Calcium Silicate Hydrate

2. $\mathrm{Ca}(\mathrm{OH})_{2}$ Calcium hydroxide

\section{Cement Hydration Equation:}

$$
\text { Cement }\left(\mathrm{C}_{3} \mathrm{~S}, \mathrm{C}_{2} \mathrm{~S}\right)+\mathrm{H}_{2} \mathrm{O} \rightarrow \mathrm{CSH} \text {-gel }+\mathrm{Ca}(\mathrm{OH})_{2}
$$

\section{Basalt Fibre Reaction:}

$$
\mathrm{Ca}(\mathrm{OH})_{2}+\mathrm{SiO}_{2} \rightarrow \mathrm{CSH} \text {-gel }
$$

Basalt fibre has a high content of $\mathrm{SiO} 2$, which reacts with the $\mathrm{Ca}(\mathrm{OH}) 2$ produced by the hydration of Portland cement.
As a result, it will form more $\mathrm{CSH}$ that is responsible for increasing the general strength of the concrete, Mochamad Solikin [18].

Basalt fibre is a multi-performance fibre. It has several advantages: for example, it is non-corrosive, has high thermal resistance to heat, and it is a waste and renewable material, as well as very light in weight, Smriti Raj [31]. Its effect on the properties of concrete is similar to glass, but better in terms of thermal and alkaline resistance for concrete. It is cost effective, and easy to disperse when mixed with concrete and mortar. Therefore, basalt fibrereinforced concrete serves the functions of reinforcement and crack resistance, and can extend the life of construction in the fields of housing, bridges, highways, and roads, Arivalagan.S [1]. The current main sources of basalt fibre are east European countries, such as Russia and Ukraine, and now China. The chemical composition of basalt fibres is shown in Table 1, Van de Velde K [34].

Table 1: The chemical composition of basalt fibres

\begin{tabular}{|l|l|}
\hline Compound & $w \%$ in Basalt fibres \\
\hline $\mathrm{SiO} 2$ & $51.6-57.5$ \\
\hline $\mathrm{Al2O} 3$ & $16.9-18.2$ \\
\hline $\mathrm{CaO}$ & $5.2-7.8$ \\
\hline $\mathrm{MgO}$ & $1.3-3.7$ \\
\hline $\mathrm{B} 2 \mathrm{O} 3$ & -- \\
\hline $\mathrm{Na} 2 \mathrm{O}$ & $2.5-6.4$ \\
\hline $\mathrm{K} 2 \mathrm{O}$ & $0.8-4.5$ \\
\hline $\mathrm{Fe} 2 \mathrm{O} 3$ & $4.0-9.5$ \\
\hline
\end{tabular}

\section{CURRENT AVILABLE BASALT FIBRES ON}

\section{THE MARKET}

From reviewing the current literature on using basalt fibres, I have found out that the mechanical properties of basalt fibres obtained from different sources have different mechanical properties, however the chemical composition remained the same. The tensile strength of basalt fiber tends to vary between $2600 \mathrm{Mpa}$ to $4850 \mathrm{MPa}$, and the elongation of break of Basalt fiber varied between 2.8 and $3.1 \%$. The highest modulus of elasticity was recorded as $110 \mathrm{Gpa}$. Basalt fibres density tend to remain constant despite being supplied by different sources.Below is a list of different basalt fibre suppliers, and the mechanical properties recorded for each type:

\begin{tabular}{|c|c|c|c|c|}
\hline \multirow[t]{2}{*}{ Properties } & \multicolumn{4}{|l|}{ Supplier } \\
\hline & $\begin{array}{l}{[5]} \\
\text { Basaltex } \\
\text { (Belguim) }\end{array}$ & $\begin{array}{l}{[2]} \\
\text { AlBarrie } \\
\text { Ltd } \\
\text { (Canada) }\end{array}$ & $\begin{array}{l}{[22]} \\
\text { Pioneer } \\
\text { Scientific } \\
\text { ( China ) }\end{array}$ & $\begin{array}{l}{[17]} \\
\text { Mafic } \\
\text { limited } \\
\text { (UK) }\end{array}$ \\
\hline $\begin{array}{l}\text { Density } \\
\mathrm{g} / \mathrm{cm}^{3}\end{array}$ & 2.67 & 2.7 & 2.8 & 1.85 \\
\hline
\end{tabular}

Table -2: Available basalt fibers on the Market 


\begin{tabular}{|l|l|l|l|l|}
\hline $\begin{array}{l}\text { Modulus of } \\
\text { Elasticity } \\
\text { GPa }\end{array}$ & 84 & 89 & $93-110$ & $84-88$ \\
\hline $\begin{array}{l}\text { Elongation } \\
\text { to break }\end{array}$ & 2.8 & 3.15 & 3.1 & - \\
\hline $\begin{array}{l}\text { Tensile } \\
\text { Strength } \\
\text { MPa }\end{array}$ & - & 4840 & $\begin{array}{l}4100- \\
4840\end{array}$ & $\begin{array}{l}2600- \\
3000\end{array}$ \\
\hline
\end{tabular}

\section{COMPOSITE STRENGTH OF A MATERIAL}

\section{CONTAINING FIBRES AND AGGREGATES}

In each material, stress is determined by its modulus of elasticity. Materials with high modulus of elasticity can resist higher stress than materials with low modulus of elasticity. In practice, composites that contain low modulus of elasticity are reinforced by fibres with different proportions to enhance strength and stress resistance. Therefore, the addition of fibres to composite materials is essential to enhance their modulus of elasticity. For example, from Figure 1 it is clear that the content of fibres in the composite material is relatively high. As a result, the composite material will be capable of resisting higher stress, and the failure of the matrix will be hardly noticed. Therefore, the total load will be carried by fibres before it reaches a failure point. Now consider Figure 2: fibre content is very low, and up to a certain level, the addition of fibres reduces the strength of the composite. Fibres will fail first: the major portion of the load will be transferred to the composite, which is incapable of carrying this load, and an immediate failure will occur. Therefore, the addition of fibres with different proportions to the composite will have a significant effect on the modulus elasticity of the material.

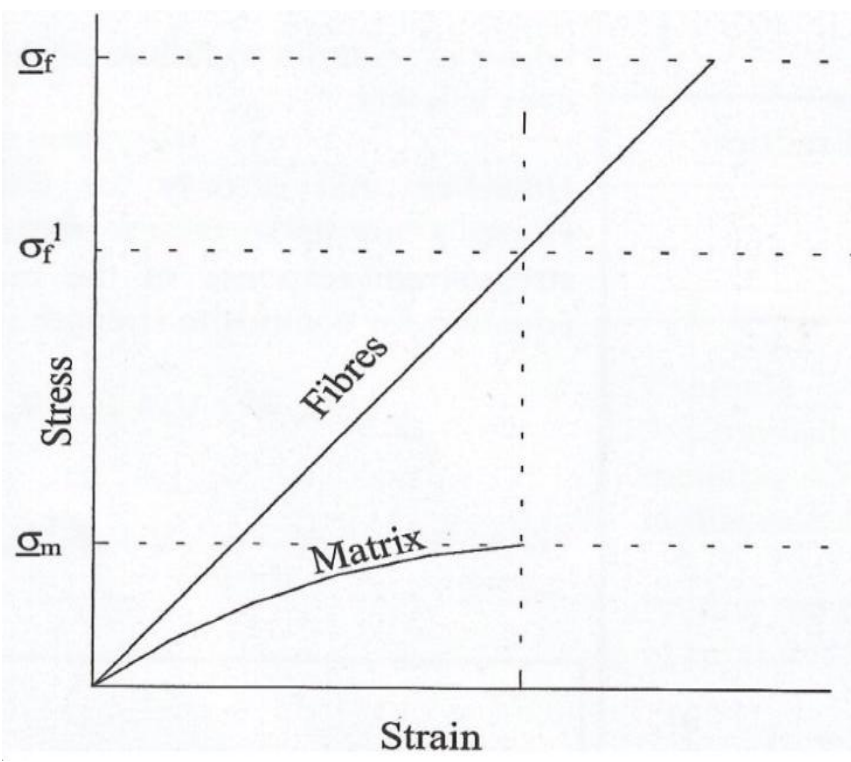

Fig. 1: High fibre content in a composite material [25]

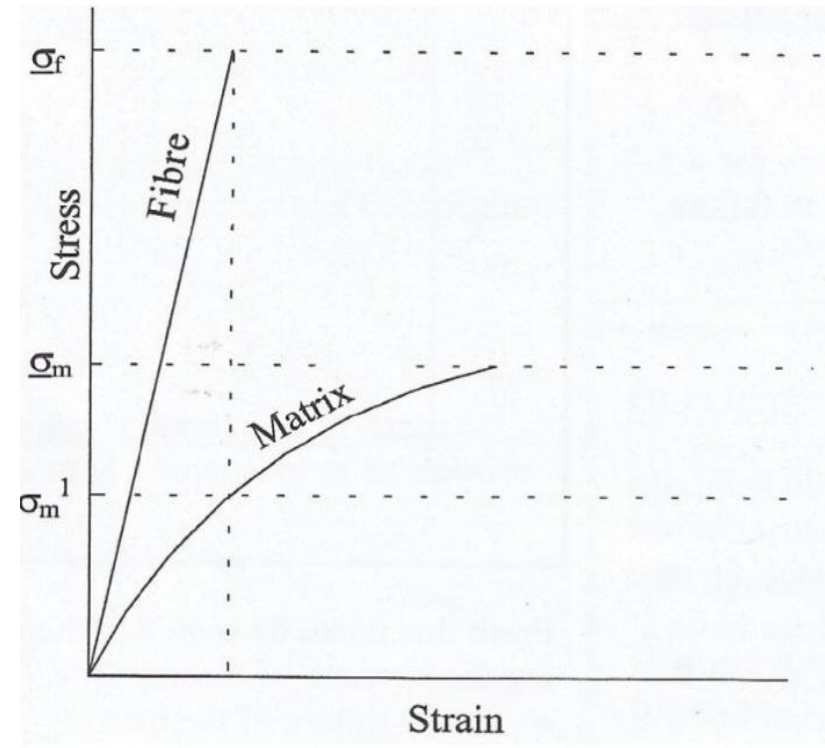

Fig. 2: Low fibre content in a composite material [25]

On the other hand, aggregates play an essential role in absorbing and reducing stress on a matrix. When load is applied, failure occurs in aggregates not only through aggregate-mortar interface, but also through the aggregates themselves. In particular, aggregates tend to fail and break when high load is applied. Therefore, it is essential to test the ability of aggregates to withstand load, and determine the effect of aggregates on the stress-strain relationship of concrete.

\section{EFFECT ON THE MECHANICAL PROPERTIES OF CONCRETE OF ADDING BASALT FIBRES OF DIFFERENT LENGTHS AND PROPORTIONS}

The principal effects of basalt fibres on the mechanical properties of concrete are: they can react chemically with the cement, producing more $\mathrm{CSH}$ which is required to increase the concrete strength; they are capable of reducing crack propagation, thus enhancing the tensile strength of concrete; and they also have high thermal and alkaline resistance, which improves the durability of concrete. Therefore, the effects on the mechanical properties of using basalt fibres of different lengths and proportions are as presented below.

Workability: Workability is the ease with which a fresh mix of concrete or mortar can be handled and placed. It is also defined as the ability of the concrete mix to fill in the shape of a form/mould with the desired work, and without reducing the concrete quality. Several factors affect the workability of fresh concrete: water content, aggregate shape, mix proportions, grading of aggregates, and the use of fibres. Workability of concrete is measured using a slump test; the addition of fibres can change the water cement ratio and, as a result, reduce its slump. Jianxun Ma [16], in his study of the influence of pre-soaked basalt fibre on the mechanical properties of concrete, found that the slump of 
concrete reinforced with basalt fibre is reduced with an increase in the content and length of the basalt fibre. Different basalt fibre lengths of $10 \mathrm{~mm}, 20 \mathrm{~mm}$ and $30 \mathrm{~mm}$ were used with different dosages of 3,5 and $7 \mathrm{~kg} / \mathrm{m} 3$. The decrease in slump occurred for two main reasons: the increase of the coefficient of friction between fibres and cement during mixing; and the absorption of certain moisture by the basalt fibre, causing the slump to reduce. Tumadhir and Borhan [33] observed the influence for workability of reinforcing concrete with different basalt fibre contents $(0 \%, 0.1 \%, 0.2 \%, 0.3 \%, 0.4 \%, 0.5 \%)$. The results showed that increasing the percentage volume of fibres leads to a decrease in slump. This is because basalt fibres affect the flowability of fresh concrete, which results in a decrease in workability. Experimental results obtained by R.Singaravadivelan [28] showed that, as the fibre content increases in concrete, the slump of fresh mixed concrete of different basalt fibre content decreases, as well as the workability. Basalt Fibre Research worldwide [4] studied the mechanical properties of concrete reinforced with three types of basalt fibres. Different concrete matrix compositions, reinforced with different basalt fibre content, were tested. The results showed that the slump of concrete reduces as the basalt fibre content increases.

Compressive Strength: The compressive strength of concrete is the most common performance measure used by civil engineers in designing buildings. Compressive strength is defined as the capacity of materials to withstand load that reduces its size. In general, concrete is strong in compression and can exhibit high strength. However adding different basalt fibre lengths and content has an effect on the compressive strength of concrete. Arivalagan [1] carried out investigations on concrete using cubic and cylindrical tests to determine the average compressive strength of three samples, mixed with and without basalt fibres, at 7, 14 and 28 days. The results showed that the average compressive strength for the basalt fibre concrete samples was higher than the compressive strength of the normal concrete samples at 7, 14 and 28 days. The variation of concrete compressive strength mixed with different basalt fibres content of $0.1 \%$ to $0.5 \%$ was explained by Tumadhir and Borhan [33] as follows. The compressive strength of concrete increases with increasing basalt fibre content up to $0.3 \%$ : after this, the concrete compressive strength tends to decrease gradually by $12 \%$. This is due to the cohesive decrease between the cement paste and the aggregate that plays a significant role in the compressive strength of concrete. The basalt fibre length that was used was $24.3 \mathrm{~mm}$, with a diameter of $13 \mathrm{um}$. Palchik [21] studied the effect of using different basalt fibre lengths of $12 \mathrm{~mm}$ and $24 \mathrm{~mm}$ on the compressive strength of concrete, using a cubic sample with dimensions of $100 \times 100 \times 100 \mathrm{~mm}$. In total, 126 concrete samples were tested: 18 of the samples were not reinforced, while 108 were reinforced, with basalt fibres. The results showed that the compressive strength of concrete increases by $58 \%$ when reinforcing concrete with basalt fibre $12 \mathrm{~mm}$ in length, and increases by $25 \%$ when reinforcing concrete with basalt fibre $24 \mathrm{~mm}$ in length. Jianxun Ma [16] states that adding pre-soaked basalt fibres to concrete with different dosage and length does not increase the compressive strength: however, it changes the fracture pattern of the concrete from brittle to tough, improving mainly the concrete compressive toughness. Wang Jun and Zhang Ye [35] have shown that, as the basalt fibre content increases in the concrete mixture, the compressive strength of the concrete decreases, when testing concrete strength after 7 days. However, when testing concrete strength after 28 days, the compressive strength of the concrete increases with an increase in basalt fibre content to reach its maximum value at fibre content of $0.1 \%$.

Tensile Strength: Although concrete is weak in tension, the knowledge of concrete tensile strength is essential to determine the load under which cracks will develop. This load has an influence on the formation of cracks and their propagation to the tension side of the concrete and other concrete members. Reinforcing concrete with basalt fibres reduces the crack width, thus improving concrete strength and durability. The results obtained by Arivalagan [1] showed that the tensile strength of concrete reinforced with basalt fibres increases with the age of curing. Concrete tensile tests were carried out on concrete samples reinforced with and without basalt fibres. The specimens were kept in water for curing for 7 days, 14 days and 28 days, and on removal were tested by spraying water on the concrete. The results showed the tensile strength of concrete gradually increases with curing age. Jianxun Ma [16] found that the tensile strength of concrete increases as the length of the pre-soaked basalt fibres increases. The author has investigated the effect of using different basalt fibre lengths of $10 \mathrm{~mm}, 20 \mathrm{~mm}$ and $30 \mathrm{~mm}$ on the tensile strength of concrete. The results showed that using $30 \mathrm{~mm}$ basalt fibre achieved the highest tensile strength. Budkonstruktsiya (for Technobasalt-Invest LLC) [6] has studied the influence of fibre concrete reinforcement on the tensile strength of concrete, with lengths of $12 \mathrm{~mm}, 24 \mathrm{~mm}$ and $50 \mathrm{~mm}$, and content of $1 \%-3 \%$, of basalt fibre. The following conclusions were drawn from the results. Using $12 \mathrm{~mm}$ basalt fibre with 1-2\% content results in achieving higher concrete tensile strength of the B20 class; in addition, reinforcing concrete with basalt fibre $24 \mathrm{~mm}$ and $50 \mathrm{~mm}$ in length, with 1-3\% content, increases the tensile strength significantly by 1.79 times. Although most fibre lengths achieved higher tensile strength, there was not a significant difference when using $24 \mathrm{~mm}$ and $50 \mathrm{~mm}$ fibre lengths. Gore Ketan [12] states that adding $1 \%$ content of basalt fibre to the mixture reduces the tensile strength of the concrete. Feng Chen [8] determined the tensile strength of basalt fibre reinforced concrete after 28 days, and the results showed that the tensile strength of the concrete improved significantly by $19 \%$.

Flexural Strength: In the construction and engineering field, knowing some terms such as the flexural strength of the material is essential in order to make sure that the material is strong enough to be used in structures. According to Elayesh [7], flexural strength is defined as the material's ability to resist deformation under load. Elayesh [7] provides two useful main parameters: determining the first crack 
strength that the material can withstand, and the ultimate flexural strength or modulus of rupture, which is determined by the maximum load that can be attained. Gore Ketan [12] has measured the flexural strength of concrete after 7 days, with and without the addition of basalt fibres. The results show that as $1 \%$ of basalt fibre is added to concrete, the flexural strength decreases. Wang Jun and Zhang Ye [35 carried out investigations to determine the mechanical properties of concrete, the compressive strength, splitting resistance, and flexural resistance, by reinforcing concrete with non-dipping chopped basalt with a length of $30 \mathrm{~mm}$, and using different content of $0.1 \%, 0.15 \%, 0.2 \%, 0.25 \%$, $0.3 \%$ and $0.35 \%$. The results show that the flexural strength of the concrete increased as the basalt fibre content increased, reaching its maximum value when the basalt fibre content was $3 \%$. From the results of an experiment, AlBaijat [13] has shown that, as the basalt fibre content increases, the flexural strength of the concrete increases. The author used different basalt fibre content $(0 \%, 25 \%$, $50 \% .75 \%$ and $100 \%$ ), tested in a laboratory using different concrete prisms. The results were compared with a normal concrete mixture, and it is clear that adding basalt fibres to the concrete mixture increases the mechanical properties in general, including the flexural strength Solikin [18] has examined the mechanical properties of high volume ultra ash concrete to gain higher strength at an early stage. Basalt fibres were mixed with concrete and the results were compared with ordinary Portland cement. The author carried out flexural concrete strength tests using prisms for different samples. The results showed that the flexural strength of concrete increases for all concrete mix proportions with age. This shows that the contribution made by mixing basalt fibres with concrete increases its flexural strength.

Elastic Modulus: The elastic modulus is a measure of the material stiffness and its tendency to deform elastically. From Hook's law, the modulus of elasticity (or Young's modulus) is defined as the ratio of the stress to the strain, and can be represented by the slope of the stress strain diagram. Various researchers have investigated the influence of adding basalt fibres with different proportions and lengths to the elastic modulus of concrete. Tumadhir and Borhan [33] found experimentally that increasing the basalt fibre content from $0.1 \%$ to $0.3 \%$ increases the modulus of elasticity of concrete significantly. In particular, the highest modulus of elasticity was achieved when the basalt fibre content was $0.3 \%$, and it started to decrease as the basalt fibre content reached $0.5 \%$. Ayub [32] observed that the addition of basalt fibres to concrete enhances the elastic modulus of concrete. The author has discovered that the slope of the stress strain curve of the control mix is steeper than those curves reinforced by basalt fibres. Three different proportions of basalt fibre content were used in these experiments: $1 \%, 2 \%$ and $3 \%$. The results indicate that basalt fibres were fully active and showed excellent resistance to the crack propagation of concrete. Palme [15] has investigated the effect of adding different basalt fibre content of $0.06 \%, 0.2 \%$ and $0.8 \%$ into the concrete stress strain curves, and found that adding basalt fibre content of $0.2 \%$ achieves the highest stress strain resistance values.
Huijun $\mathrm{Wu}$ [14] investigated the effect of reinforcing concrete with different fibres and studied their influence on the concrete elastic modulus. The fibres tested are polyethylene, glass, and basalt fibres. All concrete samples were subjected to cycles of freeze thaw and the elastic modules of concrete were then determined. The results showed that the elastic modulus of basalt fibres remained unchanged after various freeze thaw cycles. The elastic modulus of the ordinary concrete value dropped as further freeze thaw cycles were applied to the concrete. This is due to the capability of basalt fibres to reduce cracks and resist temperatures, which improves the internal structure of concrete. Ayub [32] studied the effect on the mechanical properties of concrete (including the elastic modulus) of reinforcing concrete with different basalt fibre content of $1 \%, 2 \%$ and $3 \%$. The results showed that, as the basalt fibre content increases, the elastic modulus of concrete increases, and that basalt fibre plays an important role in enhancing the mechanical properties of concrete, including the elastic modulus. Poznyak [20] showed that adding different basalt fibre lengths of $6 \mathrm{~mm}, 12 \mathrm{~mm}, 24 \mathrm{~mm}$ and $36 \mathrm{~mm}$ to selfcompacted concrete increased its elastic modulus significantly. The results were compared with selfcompacted concrete that contained no fibres.

Permeability: Concrete is a porous material that allows moisture movement through it by three modes: flow, diffusion, and sorption. Large pores allow easier entry of substance, while smaller pores decrease the rate at which these substances enter the concrete. The rate of fluid flow in concrete by these three modes is referred to as permeability. In order to determine the permeability of concrete, the water penetration or the chloride ion penetration should be measured. Various studies have been conducted to investigate the relationship between adding basalt fibres and water permeability. Jianxun Ma [16] studied the influence of different volumes $(3,5$ and $7 \mathrm{~kg} / \mathrm{m} 3)$ and lengths $(10 \mathrm{~mm}$, $20 \mathrm{~mm}$ and $30 \mathrm{~mm}$ ) of basalt fibre on concrete permeability and workability. The results showed an increase in the concrete water permeability and a decrease in concrete workability by the same amount. A Fibres Unlimited report [11] evaluated the effect of basalt fibre content (1\% and 3\%) on water permeability and penetration resistance using permeability tests. It was found that the permeability of concrete improved significantly when increasing the content of basalt fibres in the mixture. This is because basalt fibres that are well mixed and distributed throughout concrete have excellent cohesive properties, which reduces the porosity of concrete. Huijun $\mathrm{Wu}$ [14] has studied microstructures and permeability using three different types of fibre: basalt, glass and polyethylene. The study was carried out using the rapid chloride permeability test, which measures the amount of ions passing through a concrete sample reinforced with fibres. All results were compared with a sample of an ordinary concrete. The results showed that the ordinary concrete achieved the highest results, followed by glass and basalt fibres, and finally polyethylene fibres. The results indicate that basalt fibres have a reasonable level of permeability. 
Unit Weight: The unit weight of concrete, or density, is a measure of volume per unit weight and is expressed in $\mathrm{kg} / \mathrm{m} 3$. The significance of measuring the unit weight of concrete is that it is an effective indicator of the uniformity of raw materials during mixing, batching, placing, sampling and testing. A significant change in the unit weight signals a change somewhere in the process. Experimental results obtained by Tumadhir and Borhan [33] showed that, as the basalt fibre content increases in the concrete mixture, the unit weight remains constant. Gopinath [30] has examined the effect of using different volume fractions of basalt fibres on the concrete unit weight. The range of fibres used in this research ranged from $0.3 \%$ to $2 \%$. Different failure modes were observed for each volume fraction of fibres under compressive loading. The results showed that adding more fibre content by volume to the concrete mixture increases slightly the density of the concrete.

\section{SIGNIFICANCE OF THE STUDY}

The use of basalt fibres in a range of industrial applications has increased significantly over the last decade. The possibilities of utilising basalt fibres with materials are now being realized, as a result there are now numerous examples where basalt fibres have found application in a number of diverse sectors. In general, the construction industry constitutes the largest sector to employ basalt fibre materials on its products. For example chopped fibers are used mainly in the building of foundations, wall panels, slab floors, and for reinforcing of asphalt concrete road. For volumetric formed reinforcement needs about $2-5 \mathrm{~kg}$ of basalt chopped fibre for 1 metric cubic concrete ( one cubic includes about 100 flimate fibres with length of $12 \mathrm{~mm}$ ). Results of the volumetric formed reinforcement in the hardened concrete include: (Basalt fibre \& composite materials [3] )

○ Compressive strength to be increased by $20-25 \%$,

- Tensile load increase by $200-230 \%$,

- Freeze resistance by $1.6-2$ times,

$\circ \quad$ Gain of crack growth resistance under load

Further tests were carried out to determine the significance of adding chopped basalt fibres to concrete in the construction industry, and the results showed that: (Global Eco Distributors [11])

1. Adding 1 to $5 \mathrm{~kg}$ of basalt fiber to B25 per $1 \mathrm{~m}^{3}$ concrete increases tensile strength at bending up to $29 \%$. Compressive strength increases by $14 \%$.

2. Adding 1 to $4 \mathrm{~kg}$ of basalt fiber to B30per $1 \mathrm{~m}^{3}$ concrete increases tensile strength at bending up to $29 \%$. Compressive strength increases by $9 \%$.

Basalt fiber reinforced concrete can extend the life cycle of bridges, highways, housing, sea structures, tunnels. The level of improvement achieved, compared to plain concrete, depends on the dosage rate that is added to the concrete mixture. According to a new report titled " the global continuous basalt fiber market [10] was valued at USD 51.4 million in 2012 and is expected to reach USD 104.7 million in 2019, growing at a rate of $10.9 \%$ between 2013 and 2019. As a result, the significance of this study is to provide recommendations to the construction industry to use the best proportion of basalt fibre material composition that can enhance the mechanical properties of concrete. Therefore, this research will serve as a theoretical model for using basalt fibers in concrete for future studies on the same nature.

\section{CONCLUSION}

Based on this literature, the effect of basalt fibre length and content on workability showed that the slump decreases as the content of basalt fibres increases. Most authors agreed that the maximum compressive strength is reached when the basalt fibre content is $0.25 \%$; this drops as the fibre content increases. The maximum compressive strength using different basalt fibre lengths was achieved when using basalt fibre lengths between 10 and $20 \mathrm{~mm}$. The literature also confirmed that adding different basalt fibre content to improve the tensile strength of concrete has a significant effect. The longer the basalt fibres used in the mixture, the higher the tensile strength achieved. Moreover, the literature agreed that increasing both content and length of basalt fibres in reinforced concrete increases the flexural strength, elastic modulus, and crack resistance of concrete. The literature showed that concrete reinforced with basalt fibres of different lengths and content achieves a higher level of permeability and less porosity. This is because basalt fibres can bond chemically with the cement, which decreases the number of pores in concrete, and consequently enhances its permeability.

\section{ACKNOWLEDGEMENTS}

I am thankful to Dr. Gareth Whittleston for his contribution in this study.

\section{REFERENCES}

[1]. Arivalagan.S, 2012, Study On the Compressive and Split Tensile Strength Properties of Basalt Fibre Concrete Members, Global Journal of Researches in Engineering Civil And Structural Engineering, Volume 12 Issue 4 Version 1.0 Year 2012, PP 23-27 Type: Double Blind Peer Reviewed International Research Journal, Publisher: Global Journals Inc. (USA), Online ISSN: 2249-4596 \& Print ISSN: 0975-5861, available from www.globaljournal.org [2]. Albarrie Ltd, 2014, Basaly fabric properties of basalt fibre, available from www.albarriefabrics.com/basalt-fabric [3]. Basalt Fiber \& composite materials technology development, Basalt continuous fibers materials production, $2005 \quad-\quad 2014, \quad$ available from http://basaltm.com/en/bazaltovye-porody/basalt-continuousfibers-materials-production.html

[4]. Basalt Fiber Research worldwide 2010, Report of Material Testing on Basalt Fibre Mortars, Testing Report, Basalt Fibres Products of high quality, available from www.basaltfiberworld.blogspot.co.uk

[5] Basaltex Products, 2008, the tread of stone, chopped basalt fibres, Belgium, available from http://www.basaltex.com/index.html 
[6]. Budkonstruktsiya LLC, Technobasalt-Invest, 2013 Technobasalt-Invest, Test conclusions on tensile strength in bending of basalt fiber concrete. Results obtained by the Research and Development enterprise Budkonstruktsiya LLC, available from http://www.technobasalt.com

[7]. Elayesh S. M. 2009, Performance of laterite aggregate concrete, Un-published by University Teknologi, Malaysia, Report available from http://eprints.utm.my/11401/3/SalemMohamedElayeshMFK A2010ABS

[8]. Feng Chen 2013, An experimental Study on Mechanical properties of Basalt fiber reinforced concrete, Progress in industrial and Civil Engineering 2, Applied Mechanics and Materials ( Volumes 405-408 ), PP 2767-2770, available from http://www.scientific.net/

[9] Fibres Unlimited Report 2013, Test Report Of Basalt Fiber Reinforced Concrete And Polypropylene fibre reinforced concrete, BIC: ABNANL2A, THE NETHERLANDS, available from http:/www.basatfibres.com

[10]. Global Continuous Basalt Fiber Market, 2014, Sheela AK, available from http://www.prnewswire.com

[11].Global Eco Distributors, Basalt, 2013. Available from www.globalecodistributors.com

[12] Gore Ketan 2012, The Performance of basalt fibre in high strength concrete, Journal of Information, Knowledge and Research in Civil Engineering, ISSN: 0975-6744/Nov 12 to Oct 13/ Volume 2, Issue 2, PP 117-123, available from www.ejournal.aessangli.il

[13] Hamadallah Mohammad Al-Baijat 2012, The Use of Basalt Aggregates in Concrete Mixes in Jordan, Department of Civil Engineering, Faculty of Engineering, Tafila Technical University, Jordan Journal of Civil Engineering, Volume 2, No. 1, 2008, PP 63-70, available from https://elearning.just.edu.jo

[14] Huijun Wu 2013, Study on Micro-Structure and Durability of Fiber Concrete, Research Journal of Applied Sciences, Engineering and Technology Volume 5(2): PP 659-664, 2013, ISSN: 2040-7459; E-ISSN: 2040-7467, Maxwell Scientific Organization, 2013, available from http://maxwellsci.com

[15] Jahi Palme 2014, Investigation of the Addition of Basalt Fibres intoCement, Masters Theses \& Specialist Projects, Western Kentucky University, Free acess byTopSCHOLAR

[16] Jianxun Ma 2010, Experimental Research on the Fundamental Mechanical Properties of Presoaked Basalt Fiber Concrete, CICE 2010 - The 5th International Conference on FRP Composites in Civil Engineering, September 27-29, 2010 Beijing, China, PP 1-4, available from http://www.iifc-hq.org/proceedings/CICE_2010

[17] Mafic limited ( Uk ), 2014, chopped basalt fibres, available from http://www.maficbasalt.com/

[18] Mochamad Solikin 2012,High Performance Concrete with High Volume Ultra Fine Fly Ash Reinforced with Basalt Fibre, A thesis submitted in fulfillment of the requirements for the degree of Doctor of Philosophy, School of Civil, Environmental and Chemical Engineering RMIT University Melbourne, Australia 2012
[19] NRMCA 1994, National ready mixed concrete association, Technical information report, CIP 24, Synetic fibers for Concrete, Concrete in Practise, available from www.prestigeconcreteproducts.com

[20] O.R. Poznyak 2014, PROPERTIES OF SELFCOMPACTING CONCRETE WITH BASALT FIBER, Lviv Polytechnic National University, Department of Building Production, Report code UDK 574.63+546.3+54414

[21] Palchik P.P. 2011 , Kyiv National University of Construction and Architecture Protocol No 64-1-11, on control testing of fiber-concrete samples to determine their compression and tensile strength at bending.

[22] Pioneer Scientific Industry (Nanjing) Co, 2014, chopped basalt fibres, available from http://www.ppfiber.com/ [23] PROTOCOL № 64-1-11 on control testing of fiber-concrete samples to determine their compression and tensile strength at bending, available from http://usbasalt.com

[24] P.K. Mehta 2013, and P.J.M. Monteiro, Concrete: Microstructure, Properties, and Materials,ISBN-10: 0071797874 | ISBN-13: 978-0071797870 | Edition: 4, McGraw-Hill Professional.

[25] Quinn, 2007, Composites - Design Manual, $4^{\text {th }}$ Edition, ISBN: 09534654-3-8 Liverpool, James Quinn Associates Ltd.

[26] Richard E.Prince 2013, Prince Engineering Plc, Inclusive Engineering, Build on Price 2010-2014, available from http://www.build-on-prince.com/basalt-fiber

[27] R. Karthigeyan 2013, Review of Al Metal Matrix Composite and Basalt Fiber as a New Reinforcement for MMC, Life Science Journal 2013; volume 10(7s), PP 552557. Available from http://www.lifesciencesite.com

[28] R.singaravadivelan 2012, An Experimental Study has been carried out to Evaluate the Behavior of Concrete Elements using Basalt Chopped Strands Fiber, International Conference on Chemical, Bio-Chemical and Environmental Sciences (ICBEE'2012) December 14-15, 2012 Singapore PP 31-34.

[29] S.M.Chikhalikar 2012, and S.N. Tande , an experimental investigation on character properties of fibre reinforced concrete containing waste glass powder as pozolana, $37^{\text {th }}$ conference on our world in concrete \& structures: 29-31 August 2012, Singapore Article Online id:100037017, CI-Premier PTE Ltd.

[30] Smitha Gopinath 2013, Compressive behavior of Basalt Fiber Reinforced Composite, International Journal of Structural Analysis \& Design - IJSAD Volume 1 : Issue 1, PP 49-53, available from http://www.seekdl.org

[31] Smriti Raj 2013, Compressive behavior of Basalt Fiber Reinforced Composite, International Journal of Structural Analysis \& Design - IJSAD Volume 1 : Issue 1, PP 49-53, available from http://www.seekdl.org

[32] Tehmina Ayub obe 2014, Effect of Chopped Basalt fibers on the mechanical properties and the microstructure of high performance fiber reinforced concrete, advances in material science and engineering, available from http://www.hindawi.com/journals 
[33] Tumadhir M., Borhan 2013, Thermal and Mechanical Properties of Basalt Fibre Reinforced Concrete, World Academy of Science, Engineering and Technology, Volume 7, PP 712-715, available from www.waset.org

[34] Van de Velde K 2012, basalt fibers as reinforcement composites, Van de Velde K., Kiekens P., Van Langenhove L.Department of Textiles, Ghent University, Technologiepark 907, B-9052 Zwijnaarde, Belgium

[35] Wang Jun, Zhang Ye 2010, Experimental Research on Mechanical and Working Properties of Non-dipping Chopped Basalt Fiber Reinforced Concrete, 2010 3rd International Conference on Information Management, Innovation Management and Industrial Engineering. 2010| Volume 4 | PP 635 - 637. China

[36] Youjiang Wang 2000, concrete reinforcement with recycled fibres, Joournal of materials in civil engineering/November 2000, Special issue, Ecocementations materials, PP 314-319, Volume 12

\section{BIOGRAPHIES}

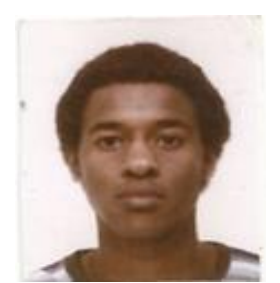

Am a Design Civil Engineer and a PhD Student with a research interest and working experience in Civil Engineering Projects. After graduating from the University of Nottingham with Master Degree in Civil Engineering, I have worked in the construction industry in various civil engineering projects and then undertook a PhD some time later. My current main research interests focus on Concrete, alternative building materials, and using advanced concrete materials in the construction industry. I am also active in the relevant civil engineering professional institutions, and have lectured students at the university. I am a Graduate Member of both the Institution of Civil Engineers and the Institution of Structural Engineers.

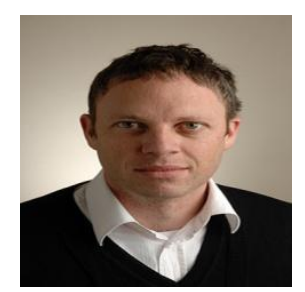

Prior to joining Bolton University, I worked in the construction industry and in research consultancy. My current main research interests focus on structural glass design and innovative uses for fibre-reinforced polymer composites in civil engineering, while I am also keen on developing and applying new technologies in the teaching of civil engineering.I am also active in the relevant civil engineering professional institutions, have been a guest speaker at various technical meetings, was awarded runner-up at the IstructE YRC09 and have presented my research findings at conferences.I am a Graduate Member of both the Institution of Civil Engineers and the Institution of Structural Engineers 